\title{
Risk factors for chronic kidney disease among patients at Olabisi Onabanjo University Teaching Hospital in Sagamu, Nigeria: A retrospective cohort study
}

\author{
Temitope W. Ladi-Akinyemi ${ }^{1}$, Ikeoluwa Ajayi ${ }^{2}$ \\ 1. Department of Community Health and Primary Care, College of Medicine, University of Lagos, Idi Araba, Nigeria \\ 2. Department of Epidemiology and Medical Statistics, University of Ibadan. Ibadan, Nigeria \\ Correspondence: Dr Temitope W. Ladi-Akinyemi (twladi-akinyemi@cmul.edu.ng)
}

\section{Background}

\section{Abstract}

Chronic kidney disease (CKD) is common and often goes undetected and undiagnosed until the disease is well advanced and kidney failure is imminent. It is estimated that approximately 36 million Nigerians suffer from different stages of CKD, as one in seven Nigerians has kidney disease.

Methods

This research was a retrospective cohort study of 150 cases and 300 controls. Selection of subjects was by a retrospective review of records of in-patients from 2010-2013 in a state teaching hospital. Data was analyzed using Chi-square at 5\% level of significance.

Results

Majority of subjects were between ages $20-29$ years. The mean (SD) age of the cases was 40.6 (14.4) and controls was 38.6 (15.8). Ninety $(60 \%)$ of the cases and $212(70.7 \%)$ of the controls were males $(p=0.023)$. Almost $87 \%$ of the cases and $42 \%$ of the controls ingest herbal concoction. Use of bleaching substances was more among the cases $20(13.4 \%)$ compared with the controls $2(0.7 \%),(\mathrm{p}=$ $0.001)$. Eight $(5.3 \%)$ of the cases had family history of $\mathrm{CKD}$ while only $1(0.3 \%)$ of the control had similar history $(\mathrm{p}=0.001)$. There were more cases $(10.7 \%)$ with diabetic mellitus compared with the controls $(2.7 \%),(p=0.001)$. The number of cases with high blood pressure was more than the number of controls, ( $\mathrm{p}$-value $<0.001$ ). Sixty-four percent of the cases had history of chronic use of analgesic compared with $10.3 \%$ of the controls $(\mathrm{p}<0.001)$.

\section{Conclusions}

CKD is mostly found among men in their productive age, who were either diabetic or hypertensive with history of ingestion of herbal concoction and chronic use of analgesic. Individual should engage in regular medical check, modify their life style while government and health care providers increase awareness and campaign on the causes and risk factors of CKD.

\section{Introduction}

Chronic Kidney Disease (CKD) is a worldwide health problem. ${ }^{1}$ The burden and very high cost of care is a challenge, especially in developing countries. Hospital-based data in Nigeria have reported that kidney diseases account for six to 12 percent of medical admissions and it affects young and middle age people. ${ }^{2}$ These are ages where the people are expected to be economically productive and contribute to national development. ${ }^{2}$ Chronic kidney disease has been defined as either kidney damage or a decreased glomerular filtration rate (GFR) of less than $60 \mathrm{~mL} / \mathrm{min} / 1.73 \mathrm{~m}^{2}$ for at least 3 months. ${ }^{3}$ Millions of patients around the world suffer from kidney disease. ${ }^{4}$ Sooner or later a proportion of these patients will need a form of renal replacements therapy such as dialysis or renal transplantation. ${ }^{5}$ This procedure saves lives but not without great cost, which are becoming a major issue of western countries because it accounts for a significant proportion of health expenditure. ${ }^{5}$ Epidemiological studies have shown that the incidence of chronic kidney disease is higher in the developing countries than the developed world. ${ }^{6}$ No fewer than 27 million Nigerians have chronic kidney disease (a precursor to kidney failure) with the incidence of 100 per million population (that is 15,000 new cases every year) and prevalence of 300 to 400 million (that is 45,000 living with kidney failure annually), according to the Nathan Kidney Foundation. ${ }^{7}$
Hypertension is the leading cause of kidney failure in Nigeria. ${ }^{5}$ The emergence of diabetes mellitus as an increasingly common cause has been documented in a study where diabetes mellitus constituted $28.4 \%$ of cases. ${ }^{5}$ The incidence of kidney disease cuts across most ages and the prevalence is highest among patients aged between 20 and 50 years. ${ }^{8-10}$ With $\mathrm{CKD}$, the damage to the kidneys is usually permanent. It cannot be fixed, but there are steps to help slow down the CKD and prevent the damage from getting worse. ${ }^{11}$ These steps includes: control of the blood sugar if the patients have diabetes, keep a healthy blood pressure, eat a heart healthy diet (low in salt and fat), exercise most days of the week, keep a healthy weight, do not smoke or use tobacco, limit alcohol consumption, talk to the doctor about medicines that might help protect the kidneys. If the CKD progresses to kidney failure, the patient will need dialysis or a kidney transplant in order to live. ${ }^{11}$

Many of the studies on CKD in Nigeria worked on knowledge and awareness of CKD. Hence this study aimed at determining risk factors associated with CKD among patients attending Olabisi Onabanjo University Teaching Hospital. Findings from this study will help in providing evidence - based information to appropriate intervention for this environment. 


\section{Methods}

\section{Study area}

The study was carried out in Ogun-State, South West Nigeria. Ogun State is one of the 36 States in the Federal Republic of Nigeria. It covers a total land area of $16,409.26 \mathrm{sq}$. km. The projected population of the State is 3,728098. The people of the state belong to the Yoruba ethnic group of southwest Nigeria. The main occupation in the state is farming, which is largely subsistence in scale. In the urban areas, petty trading and white-collar jobs (employees or professionals whose work is knowledge intensive, non-routine, and unstructured) are the major occupations. Ogun state has two federal hospitals, one state tertiary health facility (Olabisi Onabanjo University Teaching Hospital), 904 private health facilities, 29 secondary health facilities and 424 primary health facilities.

\section{Study site}

The study was conducted at the Olabisi Onabanjo University Teaching Hospital (OOUTH) Sagamu, Ogun state. The OOUTH is a tertiary institution with two hundred and fifty beds and serves as a referral center for other hospitals in and outside Ogun state. There are two main medical wards in the hospital, the male and the female medical ward, each of the wards accommodating a minimum of twentyfive patients. The hospital also has two dialysis machines for patients with kidney failure. Every month the hospital admits about fifteen to eighteen CKD patients. Health care financing in this hospital is out of pocket, that is patients and their relatives pay for all health care services received in the hospital including dialysis if required.

\section{Study design}

A retrospective cohort study was carried out. There were two independent cohorts: the first cohort was the cases and the second cohort was the control. Selection of subjects was a retrospective review of records of inpatients at the clinics/admissions from January 2010 to December 2013 in OOUTH, Sagamu. Those diagnosed to have CKD were selected into the study as the cases. While the control were patients that were seen at the orthopedic unit, surgery department. There was a frequency matching of one case to two controls.

\section{Study population}

\section{Case definition}

Patients with GFR of less than $60 \mathrm{~mL} / \mathrm{min} / 1.73 \mathrm{~m}^{2}$ or evidence of kidney damage for more than three months and were been managed as a case of CKD at the nephrology unit of the internal medicine department of OOUTH between January 2010 and December 2013.

\section{Control definition}

Patients who were involved in road traffic accident (RTA) and were been managed at the orthopedic unit of the surgery department of OOUTH between January 2010 and December 2013. Patients with kidney disease were excluded from the control group.

\section{Sample size estimation}

Using the formula for comparison of two proportions, ${ }^{12}$ the sample size was estimated at 150 for each group. A total of 150 cases and 300 controls were included (frequency matching of one case to two controls).

\section{Sampling technique}

The patients diagnosed with CKD from January 2010 to December 2013 were one thousand and one hundred; selection of the case notes into the study for the cases was by systematic random sampling. The sampling fraction was $1 / 7$, the sampling interval size $(\mathrm{k})$ was 7. Number 3 was randomly selected from number 1 to 7 . To select the case notes for this study, the third case note on the list was the first case note to be selected and every 7 th case note was selected for the study.

For the control, there were about three thousand three hundred and fifty orthopedic cases from January 2010 to December 2013. Selection of the case notes into the study was also by systematic random sampling. The sampling fraction was $1 / 11$; the sampling interval size $(\mathrm{k})$ was 11 . Number 5 was randomly selected from number 1 to 11 . To select the case notes for this study, the fifth case note was the first case note to be selected and every 11 th case note was selected for the study. All case notes with missing information greater than $30 \%$ were excluded from the study.

\section{Data collection}

A semi-structured proforma was used to extract variables needed from the case notes. The proforma obtained information on socio-demographic variables, admission and risk factors associated with chronic kidney diseases. The occupations of the patients were grouped into skilled, semi-skilled and unskilled. Skilled was used for a professional and civil servant, Semi-skilled was used for artisans and unskilled was used for traders or businessmen and women. Information was sought on chronic kidney disease patients and the proforma was used to extract information on their socio-demographic characteristics, lifestyle, medical history as well as drugs and diet history. The same was also done for the control group.

Four research assistants with Ordinary National Diploma (OND) in Health Information Management were trained for three days to assist with data collection. The research assistants were supervised daily. Data were extracted throughout the month of June 2014.

\section{Data analysis}

Data were entered, cleaned and analyzed with SPSS version 17. Sociodemographic categorical variables such as sex, marital status, religion, the level of education and occupation were presented as proportions. Continuous variables were presented as percentages, means, standard deviation, median and range as appropriate. Data were presented using frequency tables and charts. Chi-square test was used to test for association between risk factors and CKD. The level of significance was at 0.05 . All data were double entered to ensure data accuracy and there was a random check of data entered and the information on the case note in about $10 \%$ each for the cases and controls.

The variables included in the analysis were: risk factors of chronic kidney diseases, sociodemographic characteristics, lifestyle characteristics, medical history, and drugs and dietary history of the cases and controls.

\section{Ethical considerations}

Approval for the study was obtained from the OOUTH Ethical review Committee. Permission for the study was received from the Chairman Medical Advisory Committee of OOUTH, Sagamu. Permission to access the case note was sought from the head of the central records department. Strict confidentiality of all information and result of findings was maintained. 
Table 1: Sociodemographic characteristics of cases and controls

\begin{tabular}{|c|c|c|c|c|c|}
\hline \multirow{2}{*}{ Variable } & \multicolumn{2}{|c|}{ Subjects } & \multirow{2}{*}{ Total n (\%) } & \multirow{2}{*}{ Test statistic } & \multirow{2}{*}{ P-value } \\
\hline & Cases n (\%) & Controls n (\%) & & & \\
\hline \multicolumn{6}{|l|}{ Age (years) } \\
\hline 20 to 29 & $35(23.3)$ & $98(32.8)$ & $131(29.5)$ & \multirow{4}{*}{$\mathrm{X}^{2}=5.510$} & \multirow{4}{*}{0.357} \\
\hline 30 to 39 & $42(28.0)$ & $73(24.3)$ & $115(25.6)$ & & \\
\hline 40 to 49 & $28(18.7)$ & $57(19.0)$ & 88 (18.9) & & \\
\hline 50 to 59 & $27(18.0)$ & $38(12.7)$ & $65(14.4)$ & & \\
\hline$\geq 60$ & $18(12.0)$ & $34(11.3)$ & $52(11.6)$ & \multirow{3}{*}{$t=1.660$} & \multirow{3}{*}{0.098} \\
\hline Mean age $\pm S D$ & $40.6 \pm 14.4$ & $38.6 \pm 15.8$ & & & \\
\hline Range & 16 to 77 & 14 to 88 & & & \\
\hline \multicolumn{6}{|l|}{ Sex } \\
\hline Male & $90(60.0)$ & $212(70.7)$ & $302(67.1)$ & \multirow{2}{*}{$X^{2}=5.155$} & \multirow{2}{*}{$0.023^{*}$} \\
\hline Female & $60(40.0)$ & $88(29.3)$ & $148(32.9)$ & & \\
\hline \multicolumn{6}{|l|}{ Education } \\
\hline None & $30(20.0)$ & $24(8.0)$ & $54(12.0)$ & \multirow{4}{*}{$X^{2}=14.054$} & \multirow{4}{*}{$0.003^{*}$} \\
\hline Primary & $29(19.3)$ & $59(19.7)$ & $88(19.6)$ & & \\
\hline Secondary & $62(41.3)$ & $151(50.3)$ & $213(47.3)$ & & \\
\hline Tertiary & $29(19.3)$ & $66(22.0)$ & $95(21.1)$ & & \\
\hline \multicolumn{6}{|l|}{ Occupation } \\
\hline Student & $24(16.0)$ & $62(20.7)$ & $86(19.1)$ & \multirow{5}{*}{$X^{2}=3.651$} & \multirow{5}{*}{0.455} \\
\hline Unemployed & $8(5.3)$ & $18(6.0)$ & $26(5.8)$ & & \\
\hline Unskilled & $74(49.3)$ & $145(48.3)$ & $219(48.7)$ & & \\
\hline Semi-skilled & $28(18.7)$ & $56(18.7)$ & $84(18.7)$ & & \\
\hline Skilled & $16(10.7)$ & $19(6.3)$ & $35(7.8)$ & & \\
\hline \multicolumn{6}{|l|}{ Marital status } \\
\hline Single & $34(22.7)$ & $106(35.3)$ & $140(31.1)$ & \multirow{4}{*}{$\mathrm{X}^{2}=10.519$} & \multirow{4}{*}{$0.015^{*}$} \\
\hline Married & $108(72.0)$ & $181(60.3)$ & $289(64.2)$ & & \\
\hline Divorced & $3(2.0)$ & $1(0.3)$ & $4(0.9)$ & & \\
\hline Widowed & $5(3.3)$ & $12(4.0)$ & $17(3.8)$ & & \\
\hline
\end{tabular}

$\mathrm{SD}=$ standard deviation; ${ }^{*}=$ statistically significant $(\mathrm{P} \leq 0.05)$

\section{Results}

There were 150 cases and 300 controls in the study. Highest percentages of the cases $(28.0 \%)$ and the controls $(32.8 \%)$ were between 30-39 years and $\leq 20-29$ years respectively. The mean (SD) age of the cases and controls were 40.6 (14.4) years and $38.6(15.8)$ years respectively. Ninety $(60 \%)$ of the cases were males as well as $212(70.7 \%)$ of the controls. Males were significantly more between the cases and the controls $(\mathrm{P}$ $=0.023)$. Sixty-two $(41.3 \%)$ of the cases and $151(50.3 \%)$ of the controls had secondary education, $(\mathrm{P}=0.003)$. Seventyfour $(49.3 \%)$ and $145(48.3 \%)$ of the cases and controls were unskilled. (Table 1)

Nineteen $(12.7 \%)$ of the cases and 35(11.7\%) of the controls smoke cigarette. The mean (SD) numbers of sticks smoked / day among the cases was 6.6 (4.8) and among the controls was $2.0(1.2)$. There was a significant association in the mean difference of sticks smoked / day between the cases and the controls $(\mathrm{P}=0.001)$. Fifty-two $(34.7 \%)$ cases and $82(27.3 \%)$ controls drink alcohol, $(\mathrm{P}=0.109)$. However, there was a statistically significant association in the mean difference between the cases and the controls $(\mathrm{P}=0.004)$. One hundred and thirty $(86.7 \%)$ of the cases and $126(42.0 \%)$ of the controls ingest herbal concoction respectively. Ingestion of herbal concoction was statistically significantly more among the cases compared with the controls $(\mathrm{P}=0.001)$. Use of bleaching substances was statistically significantly more among the cases $20(13.4 \%)$ compared with the controls 2 $(0.7 \%),(\mathrm{P}=0.001)($ Table 2$)$.
Table 2: Lifestyle factors among cases and controls

\begin{tabular}{|c|c|c|c|c|c|}
\hline \multirow{2}{*}{ Variable } & \multicolumn{2}{|c|}{ Subjects } & \multirow{2}{*}{ Total n (\%) } & \multirow{2}{*}{$\begin{array}{c}\text { Test } \\
\text { statistic }\end{array}$} & \multirow{2}{*}{ P-value } \\
\hline & Cases n (\%) & Controls n (\%) & & & \\
\hline \multicolumn{6}{|l|}{ Cigarette smoking } \\
\hline Yes & $19(12.7)$ & $35(11.7)$ & $54(12.0)$ & \multirow[b]{2}{*}{$\mathrm{X}^{2}=0.095$} & \multirow[b]{2}{*}{0.758} \\
\hline No & $13(87.3)$ & $265(88.3)$ & $396(88.0)$ & & \\
\hline $\begin{array}{l}\text { Mean cigarettes per } \\
\text { day } \pm S D\end{array}$ & $6.6 \pm 4.8$ & $2.0 \pm 1.2$ & & $t=5.361$ & $0.001^{*}$ \\
\hline $\begin{array}{l}\text { Range, cigarettes per } \\
\text { day }\end{array}$ & 1 to 20 & 1 to 6 & & & \\
\hline \multicolumn{6}{|l|}{ Alcohol consumption } \\
\hline Yes & $52(34.7)$ & $82(27.3)$ & $134(29.8)$ & \multirow{2}{*}{$X^{2}=2.572$} & \multirow{2}{*}{0.109} \\
\hline No & $98(65.3)$ & $218(72.7)$ & $316(70.2)$ & & \\
\hline $\begin{array}{l}\text { Mean drinks per day } \pm \\
\text { SD }\end{array}$ & $3.7 \pm 4.1$ & $1.9 \pm 1.2$ & & $t=4.083$ & $0.004^{*}$ \\
\hline Range, drinks per day & 1 to 15 & 1 to 4 & & & \\
\hline \multicolumn{6}{|l|}{$\begin{array}{l}\text { Ingestion of herbal } \\
\text { medicine }\end{array}$} \\
\hline Yes & $130(86.7)$ & $126(42.0)$ & $256(56.9)$ & \multirow{2}{*}{$\mathrm{X}^{2}=82.443$} & \multirow{2}{*}{$0.001^{*}$} \\
\hline No & $20(13.3)$ & $174(58.0)$ & $194(43.1)$ & & \\
\hline \multicolumn{6}{|l|}{$\begin{array}{l}\text { Use of bleaching } \\
\text { substances }\end{array}$} \\
\hline Yes & $20(13.4)$ & $2(0.7)$ & $22(4.9)$ & \multirow{2}{*}{$\mathrm{X}^{2}=34.544$} & \multirow{2}{*}{$0.001^{*}$} \\
\hline No & $130(86.7)$ & $298(99.3)$ & $428(95.1)$ & & \\
\hline
\end{tabular}

Eight $(5.3 \%)$ of the cases had a family history of CKD while only $1(0.3 \%)$ of the control had a similar history $(\mathrm{P}=0.001)$. The result of blood pressure of the subjects at presentation shows that 130 cases $(86.7 \%)$ with elevated systolic blood pressure $(\mathrm{SBP})$ were statistically significantly more than the 141 controls (47.0\%), $(\mathrm{P}<0.001)$. The mean (SD) SBP of the cases was $167(40.0)$ and that of the controls was 130.3 (30.5), $(\mathrm{P}<0.001)$. One hundred and twelve $(74.7 \%)$ of the cases and $98(32.7 \%)$ of the controls had elevated diastolic blood pressure (DBP), $(\mathrm{P}<0.001)$. The mean (SD) DBP of the cases was 105 (28.6) and that of the controls was 81 (18.8). There were more cases $(10.7 \%)$ with Diabetic Mellitus compared with the controls $(2.7 \%),(\mathrm{P}=0.001)$. Ten $(6.7 \%)$ of the cases were HIV positive compared with 5(1.7\%) of the controls, $(\mathrm{P}=0.005)$. Six cases $(4.0 \%)$ with history of urinary tract infection were significantly more than one controls $(0.3 \%),(\mathrm{P}=0.006)$. Eleven $(7.3 \%)$ of the cases had cancers compared with $2(0.7 \%)$ of the controls, $(\mathrm{P}<0.001)$. (Table 3).

Regular use of non-steroidal anti-inflammatory drugs (NSAIDs) had been identified as a risk factor of CKD. Numbers of cases $(62.7 \%)$ on regular use of NSAIDs were statistically significantly more than the number of controls (11.0\%), $(\mathrm{P}<0.001)$. Ninety-six $(64.0 \%)$ had history of chronic use of analgesia compared with $31(10.3 \%)$ of the controls, $(\mathrm{P}<0.001)$. History of addition of salt to cooked food prior consumption was statistically significantly more in 92 cases $(61.3 \%)$ compared with 51 controls $(17.0 \%),(\mathrm{P}<$ $0.001)$. Consumption of can food was not significant among the cases $3(2.0 \%)$ and controls $1(0.3 \%),(\mathrm{P}=0.076)$ (Table 4).

\section{Discussion}

This study demonstrates that CKD is common among males in their early and middle age. More than $80 \%$ of the cases ingest herbal concoction and significantly higher percentage of the cases use bleaching substances compared with the controls. A larger percentage of the cases had a family history of CKD, higher blood pressure, diabetes, HIV positive, urinary tract infection and history of cancer compared with the controls. Patients with CKD also reported significantly 
Table 3: Medical conditions among cases and controls

\begin{tabular}{|c|c|c|c|c|c|}
\hline \multirow{2}{*}{ Variable } & \multicolumn{2}{|c|}{ Subjects } & \multirow{2}{*}{ Total n (\%) } & \multirow{2}{*}{ Test statistic } & \multirow{2}{*}{ P-value } \\
\hline & Cases n (\%) & Controls n (\%) & & & \\
\hline \multicolumn{6}{|l|}{$\begin{array}{l}\text { Blood pressure at } \\
\text { presentation }\end{array}$} \\
\hline \multicolumn{6}{|l|}{ Systolic (SBP) } \\
\hline $\begin{array}{c}\text { Normal } \\
(\leq 120 \mathrm{mmHg})\end{array}$ & $20(13.3)$ & $159(53.0)$ & $179(39.8)$ & \multirow[b]{2}{*}{$X^{2}=65.683$} & \multirow[b]{2}{*}{$<0.001^{*}$} \\
\hline $\begin{array}{c}\text { Elevated } \\
(>120 \mathrm{mmHg})\end{array}$ & $130(86.7)$ & $141(47.0)$ & $271(60.2)$ & & \\
\hline Mean $S B P \pm S D$ & $167.0 \pm 40.0$ & $130.3 \pm 30.5$ & $142.5 \pm 38.0$ & $\mathrm{t}=10.476$ & $<0.001^{*}$ \\
\hline \multicolumn{6}{|l|}{ Diastolic (DBP) } \\
\hline $\begin{array}{c}\text { Normal } \\
(\leq 80 \mathrm{mmHg})\end{array}$ & $38(25.3)$ & $202(67.3)$ & $240(53.3)$ & \multirow{2}{*}{$X^{2}=70.875$} & \multirow{2}{*}{$<0.001^{*}$} \\
\hline$\underset{(>80 \mathrm{mmHg})}{\text { Elevated }}$ & $112(74.7)$ & $98(32.7)$ & $210(46.7)$ & & \\
\hline Mean $\mathrm{DBP} \pm \mathrm{SD}$ & $105 \pm 28.6$ & $81 \pm 18.8$ & $89.0 \pm 28.2$ & $\mathrm{t}=10.106$ & $<0.001^{*}$ \\
\hline \multicolumn{6}{|l|}{ Hypertension } \\
\hline Yes & $91(60.7)$ & $40(13.3)$ & 131(29.1) & \multirow{2}{*}{$X^{2}=108.721$} & \multirow{2}{*}{$<0.001^{*}$} \\
\hline No & $59(39.3)$ & $260(97.3)$ & $319(70.9)$ & & \\
\hline \multicolumn{6}{|l|}{ Diabetes mellitus } \\
\hline Yes & $16(10.7)$ & $8(2.7)$ & $24(5.3)$ & \multirow{2}{*}{$X^{2}=12.696$} & \multirow{2}{*}{$0.001^{*}$} \\
\hline No & $134(89.3)$ & $292(97.3)$ & $426(94.7)$ & & \\
\hline \multicolumn{6}{|l|}{ HIV } \\
\hline Yes & $10(6.7)$ & $5(1.7)$ & $15(3.3)$ & \multirow{2}{*}{$X^{2}=7.759$} & \multirow{2}{*}{$0.005^{*}$} \\
\hline No & $140(93.3)$ & $295(98.3)$ & $435(96.7)$ & & \\
\hline \multicolumn{6}{|c|}{ Urinary tract infection } \\
\hline Yes & $6(4.0)$ & $1(0.3)$ & $7(1.6)$ & \multirow{2}{*}{$\mathrm{X}^{2}=8.779$} & \multirow{2}{*}{$0.006^{*}$} \\
\hline No & $144(96.0)$ & 299(99.7) & $443(98.4)$ & & \\
\hline \multicolumn{6}{|l|}{ Cancer } \\
\hline Yes & $11(7.3)$ & $2(0.7)$ & $13(2.9)$ & \multirow{2}{*}{$\mathrm{X}^{2}=15.842$} & \multirow{2}{*}{$<0.001^{*}$} \\
\hline No & $139(92.7)$ & $298(99.3)$ & $437(97.1)$ & & \\
\hline
\end{tabular}

$\mathrm{SD}=$ standard deviation; $*=$ statistically significant $(\mathrm{P} \leq 0.05)$

higher percentages of regular use of NSAIDS, chronic use of analgesic and addition of salt to cooked food prior consumption compared with the controls.

The mean age of the cases was 40.6 (14.2) years while that of the controls was $38.6(15.0)$ years and most of the cases and controls were less than 60years of age, a finding that is consistent with findings from similar study within and outside Nigeria where mean age of patient with CKD was 42 (15.43) years, ${ }^{13,14}$ but different from a similar studies from India where the mean age was $45.22(15.2),{ }^{15}$ Ogbomosho where the mean age of CKD patients was 50.52 (13.03) years and majority of the patients were $\geq 45$ years, ${ }^{8}$ and another study from the USA where the mean age was 62 years. ${ }^{13}$ The findings from the study in the USA with highest mean age is as a result of high life expectancy and better quality of life due to the quality of health care and health policies as well as subsidized healthcare by the US government.

The majority (28\%) of CKD patient were within the age range of 30-39, followed by age range 20-29, then 40-49 and 50-59, while the majority (26.8\%) of the controls were in the age range $20-29$, followed by age range $30-39$, then 40-49 and 50-59. This is consistent with study from Ilorin ${ }^{6}$ but different from study from Ogbomosho. ${ }^{8}$ Most of these patients are in their productive age, and this will definitely affect the economy of the country. Risk factors ascribed to chronic kidney disease in early ages are lifestyle for example consumption of alcohol, cigarette smoking, sociocultural practices such as the use of local herbs, disease states such as hypertension, diabetes mellitus, obesity, diet (high salt and protein intake, for example), sickle cell nephropathy, and infection. Most of the subjects (both the cases and controls) were males, a finding that is consistent with similar study in
Table 4: Medications and dietary habits among cases and controls

\begin{tabular}{|c|c|c|c|c|c|}
\hline \multirow{2}{*}{ Variable } & \multicolumn{2}{|c|}{ Subjects } & \multirow{2}{*}{ Total n (\%) } & \multirow{2}{*}{ Test statistic } & \multirow{2}{*}{ P-value } \\
\hline & Cases n (\%) & Controls n (\%) & & & \\
\hline \multicolumn{6}{|c|}{ Regular use of NSAIDs } \\
\hline Yes & $94(62.7)$ & $53(11.0)$ & $127(28.2)$ & \multirow{2}{*}{$X^{2}=132.083$} & \multirow{2}{*}{$<0.001^{*}$} \\
\hline No & $56(37.3)$ & $267(89.0)$ & $323(71.8)$ & & \\
\hline \multicolumn{6}{|c|}{ Chronic use of analgesics } \\
\hline Yes & $96(64.0)$ & $31(10.3)$ & $127(28.2)$ & \multirow{2}{*}{$X^{2}=192.177$} & \multirow{2}{*}{$<0.001^{*}$} \\
\hline No & $54(36.0)$ & $269(89.7)$ & $323(71.8)$ & & \\
\hline \multicolumn{6}{|c|}{ Addition of table salt to cooked food } \\
\hline Yes & $92(61.3)$ & $51(17.0)$ & $143(31.8)$ & \multirow{2}{*}{$X^{2}=90.820$} & \multirow{2}{*}{$<0.001^{*}$} \\
\hline No & $58(38.7)$ & $248(83.0)$ & $307(68.2)$ & & \\
\hline \multicolumn{6}{|c|}{ Consumption of canned food } \\
\hline Yes & $3(2.0)$ & $1(0.3)$ & $4(0.9)$ & \multirow{2}{*}{$\mathrm{X}^{2}=3.153$} & \multirow{2}{*}{0.076} \\
\hline No & $147(98.0)$ & $299(99.7)$ & $446(99.1)$ & & \\
\hline
\end{tabular}

NSAIDs $=$ non-steroidal anti-inflammatory drugs; ${ }^{*}=$ statistically significant $(\mathrm{P} \leq 0.05)$

Sagamu where more of the subjects were males, ${ }^{16}$ however the finding is different from similar study in Ogbomosho where most cases were females. ${ }^{8}$

The majority of the cases had secondary education, followed by those with no education. This can result in inadequate knowledge and awareness of CKD and its risk factors on the part of the cases regarding their lifestyle. This had been documented in another study. About half of the cases were unskilled, this is consistent with the result of a similar study in Ogbomosho where the majority of the cases were unskilled. ${ }^{8}$ Over $70 \%$ of the cases were married, this finding is consistent with similar study where most of the cases were married. $^{8}$

Larger percentages of the cases ingest herbal concoction, this could be attributed to our sociocultural belief and lifestyles, and it could also be as a result of the state of the economy in the country. It is generally believed by the less educated and the unskilled population in Nigeria that it is more expensive to go to the hospital for treatment if you are sick compared with the use of herbal concoction, this is consistent with a similar study in Nigeria. ${ }^{8}$ In addition to these, more of the cases use bleaching substances compared with the control. This is because these people are ignorant of the content of this cream/soap and the damage they can do. Furthermore, world health organization (WHO) had revealed that $77 \%$ of Nigeria women, the highest in the world use skin lightening cream on regular basis. These bleaching substances contain mercury which damages the skin and the kidney of the user. More of the cases had a family history of CKD compare with the controls. Most of the cases had elevated systolic and diastolic blood pressure at presentation. More than half of these cases were not known hypertensive. The reason for this could be as a result of people's attitude towards their health. Most Nigerians do not do routine medical checkup and by the time they are finding out that they have one chronic disease or the other, complications already set in. In most cases, it is the complication that brings them to the health facility. This could be attributed to lack of fund and ignorant on the part of the citizen and on the part of the government, it could be as a result of poor health planning and poor health facilities put in place.

The mean $( \pm$ SD) presenting systolic and diastolic blood pressure for the cases were $167.0 \pm 40.0 \mathrm{mmHg}$ and $105 \pm$ $28.6 \mathrm{mmHg}$, respectively, a finding that is consistent with the result of a similar study from Sagamu, Ogun-State, ${ }^{16}$ and that of the controls were $130.3 \pm 30.5 \mathrm{mmHg}$ and $81 \pm$ 
$18.8 \mathrm{mmHg}$. More of the cases had high blood pressure and diabetes mellitus compared with the controls. Also, more of the cases compared with the controls were HIV positive. This is because HIV reduces body immunity and can lead to several organs damage. All these risk factors were statistically significant. These findings are consistent with the result of a similar study from the USA. ${ }^{13}$

More of the cases compared with the controls had history of urinary tract infection. Urinary tract infection (UTI) alone may not cause chronic kidney disease if well treated. But if the UTI is associated with other medical conditions such as, pregnancy, diabetic, sexually transmitted infection and urinary tract abnormalities, all this may cause scarring in the kidneys which can lead to chronic kidney diseases. More of the cases compared with the controls had cancers. CKD and cancer are connected in a number of ways, cancers can cause CKD either directly such as Paraneoplastic nephropathies or indirectly through the adverse effects of the therapies.

Almost two-third of the cases compared to less than a third of the controls use NSAIDs. Likewise, more of the cases compared with the controls had history of chronic use of analgesics, this may be as a result of a lack of awareness of the side effects of these drugs on the part of the users. Another reason could be from self-medication and increase patronage of the patent medicine store instead of visiting the health facility for proper management. A finding consistent with the result of a similar study from USA. ${ }^{17}$ Majority of the cases and only a few of the controls adds table salt to already cooked food before consumption. These people might not be aware of the health implication of such practice. Study has shown that salt intake increases the amount of urinary protein which is a major risk factor for developing kidney disease and salt intake in CKD populations is generally high, and often above population average. ${ }^{18}$

\section{Study limitations}

Some of the case files were missing. Some important information was missing in some of the case files available. Some information was not properly documented. Some important information such as the weight, the height, and the body mass index were not available in the case file so risk factor such as obesity could not be analyzed.

This study assessed lifestyle risk factors retrospectively, hence, the findings from these study is subject to recall bias.

\section{Conclusions}

In this study, most CKD patients were males and females in their productive age, this may affect the economic growth of the country. The majority were unskilled and semi-skilled workers with secondary and no formal education. Hence, some of the risk factors of CKD were practiced by these people due to poor or lack of awareness of their health implications. Significant risk factors of CKD in this study were a family history of $\mathrm{CKD}$, ingestion of herbal concoction, use of bleaching cream/ soaps, elevated diastolic blood pressure at presentation, history of high blood pressure, history of cancers and history of chronic use of analgesic. Based on these findings it was recommended that Government should increase the awareness of CKD, by organizing campaigns and increasing radio jingles on the causes and risk factors of CKD especially those that are lifestyle related as well as assist in the management of CKD when it is diagnosed. Furthermore, individuals should cultivate the habit of doing routine regular medical check and modify their lifestyle.

\section{Competing interests}

All authors declare that they have no competing interests related to this work.

\section{References}

1. Hsu CY, Bates DW, Kuperman GJ \& Curhan GC. Relationship between haematocrit and renal function in men and women. Kidney Int.,2001; 59, 725-731.

2. National Kidney Foundation. Clinical Practical Guidelines for Chronic Kidney Disease, Evaluation, Classification, and Stratification. Am J. Kidney Dis, 2002;39, 51-52.

3. Alebiosu C.O. Awareness of Kidney Disorders in Nigeria. African Journal of Health Science, 2002a; 9, 3-4.

4. Ogun S.A, Adelowo O.O, Familoni O.B, Jaiyesimi A.E.A \& Fakoya C.A.O. Pattern and outcome of medical admissions at the Ogun State University Teaching Hospital Sagamu- a three-year review. West African Journal of Medicine, 2000; 19, 304-308.

5. Alebiosu C.O. Clinical diabetic nephropathy in a tropical African population, West Africa Journal med,2003a; (22)2, 152-5.

6. Chijioke A, Okoroe.O \& Makusidi A.M. Factors influencing attitude towards Kidney donation for transplantation in illnesses. Sahel medical journal, 2010; 13(2), 96-101.

7. Nathan Kidney Foundation. Raising awareness about kidney failure and its prevention amongst Nigerians;2011

8. Ulasi I. I \& Ijoma C. K. Enormity of CKD in Nigeria. The situation in a Teaching Hospital in South East Nigeria. Journal of Tropical Medicine, 2010

9. Afolabi MO, Abioye-Kuteyi EA, Arogundade FA \& Bello IS Prevalence of chronic kidney disease in a Nigerian family practice population. SA Fam Pract, 2009; 51(2), 132-137.

10. Alebiosu C.O. Awareness of Kidney Disorders in Nigeria. African Journal of Health Science. African Journal of Health Science, 2002b; (9) (3-4),9.

11. Bamgboye E.B. Haemodialysis: management problems in developing countries with Nigeria as a surrogate kid intern.2003. 63, 593-595.

12. Kirkwood B.R \& Sterne J.A.C. Essential Medical Statistics, second edition. A black well publishing company. Formulae for sample size determination. 2003; Chapter 35, 420-421.

13. Yacoub R, Habib H, Lahdo A, Ali R, Varjabedian L, Atalla G, et al. Association between smoking and chronic kidney disease: a casecontrol study. Bio-med central, 2010; 10, 731.

14. Shittu AO, Chijioke A, Biliaminu SA, Makusidi AM, Sanni MA, Abdul-rahman $\mathrm{MB}$ et al. Haematological profile of patients with chronic kidney disease in Nigeria. Journal of Nephrology and Renal Transplantation,2013; 5(1), 2-10.

15. Jerime A, Pierie Wasters R \& Pierie Wasters J . Recommendation for the screening and management of patients with CKD Nephrol- DiaTranspt., 2002; 19-28.

16. Alebiosu C O, Ayodele O O, Abbas A \& Olutoyin A I. Chronic renal failure at the Olabisi Onabanjo University Teaching Hospital, Sagamu, Nigeria. Afric Health Sc, 2002; 6(3), 132-138.

17. Vupputuri S \& Sandler D P. Lifestyle risk factors and chronic kidney disease. Annals of Epidemiology, 2003;13, 710-720.

18. Jelmer K. H, Gerjan N. Dietary Sodium Restriction: A Neglected Therapeutic Opportunity in Chronic Kidney Disease. Curr Opin Nephrol Hypertens. 2014;23 (6):533-540. 